\title{
A case of affective disorder associated with the misuse of 'anabolic steroids'
}

\author{
H. M. Perry MB and G. W. Hughes MD, MRCPsych* \\ Department of Public Health Medicine, West Glamorgan Health Authority, Swansea, UK and *Cefn Coed \\ Hospital, Swansea, UK
}

\begin{abstract}
In the pursuit of gains in muscle size and strength, body-builders may mistakenly use illicit drugs believing them to be anabolic steroids. The case described illustrates the physical and psychological dangers of such behaviour.
\end{abstract}

Keywords: Drug misuse, body-building

Anabolic steroids are widely used in body-building for gains in muscle size and strength ${ }^{1,2}$. The adverse effects which might be brought into the physician's waiting room are relatively well-documented. However, the psychiatric effects are not as clearly examined. Although some studies have noted irritability or euphoria in association with anabolic steroid use, only four reports have described more serious psychiatric problems. The first ${ }^{3}$ described a 17-yearold male bodybuilder who developed depression, paranoid ideation, and 'audible thoughts' about 6 months after starting a regimen of unknown anabolic steroids obtained illicitly. The second ${ }^{4}$ reported a 27-year-old male bodybuilder who developed euphoria, irritability, racing thoughts and hyperactivity within a few days of starting oral oxandrolone, $6 \mathrm{mg}$ twice daily. A third report ${ }^{5}$ described paranoid symptoms in four of five depressed men within a few days of taking imipramine plus methyltestosterone. In all four patients, the paranoid symptoms resolved promptly when methyltestosterone was stopped.

A case is described which has subtle differences from those described above.

\section{Case report}

A general practitioner requested psychiatric opinion for a 30-year-old man known to be taking anabolic steroids for body building. The patient presented with severe acute depression with suicidal ideas after the purchase and injection of Haldol Decanoate (Janssen Pharmaceuticals, Wantage, UK) some 4 weeks earlier in the belief that this was an anabolic

Address for correspondence: Dr H. M. Perry, Department of Public Health Medicine, West Glamorgan Health Authority, 36 Orchard Street, Swansea SA1 5AQ, UK

(C) 1992 Butterworth-Heinemann Ltd 0306-3674/92/040219-02 steroid. In the interim period the GP had prescribed dothiapen and propranolol, but the depression had persisted.

When seen by the psychiatrist, the patient admitted that he had also taken Periactin (Merck, Sharp and Dohme, Hoddesdon, UK) as an appetite stimulant. He complained of feeling profoundly depressed and suicidal, lacking energy but restless. After the injection he had experienced severe extrapyramidal symptoms and had 'slept for 4 days'.

At interview, he presented as depressed and anxious with hypochondriacal fears about permanent effects of the medication. Despite his subjective motor restlessness there were no overt extrapyramidal symptoms on examination. Procyclidine was prescribed and day-care initiated.

Some 3 days later the patient presented in crisis, emotionally distressed and complaining of akathisia (motor restlessness). He was given procyclidine intramuscularly with good effect. While the physical symptoms presented no further problems, he continued to have persistent reactive psychiatric difficulties, with loss of confidence and low self-esteem for at least the next 9 months.

\section{Discussion}

In this instance, the Haldol Decanoate was sold and mistakenly purchased as nandrolone decanoate on the basis that the common base decanoate represented the anabolic steroid. Unfortunately, the preparation not only contained a powerful injectable neuroleptic but an ester designed to produce sustained release of haloperidol over a period of up to 4 weeks.

Anabolic steroid abuse is on the increase, especially over the last 5 years. A preliminary survey by one of the authors (Perry) indicates a $38.8 \%$ prevalence in some gymnasia. The case described not only highlights problems which may be encountered when seeing patients taking anabolic steroids, but also problems which might be encountered by patients who are taking what they mistakenly think are anabolic steroids. In comparison with illicit drug misusers, individuals who abuse anabolic steroids appear to possess relatively little knowledge of the pharmacological substances they are injecting. In- 
deed, anecdotal reports indicate the abuse of such preparations as the $\mathrm{H}_{2}$ antagonist ranitidine believing it to be a steroid. For such individuals the medical and psychiatric sequelae of injecting preparations presumed to be anabolic steroids may pose a greater danger than the potential effects of the steroids themselves.

\section{References}

1 Wilson JD, Griffin JE. The use and misuse of androgens. Metabolism 1980; 29: 1278-95.
2 Haupt HA, Rovere GD. Anabolic steroids: a review of the literature. Am J Sports Med 1984; 12: 469-84.

3 Annitto WJ, Layman WA. Anabolic steroids and acute schizophrenic episode. J Clin Psychiatry 1980; 41: 143-4.

4 Freinhar JP, Alvarez W. Androgen-induced hypomania (letter). J Clin Psychiatry 1985; 46: 354-5.

5 Wilson IC, Prange AJ Jr, Lara PP. Methyltestosterone and imipramine in men: conversion of depression to paranoid reaction. Am J Psychiatry 1974; 131: 21-4.

\section{BASM news}

We report two items received as we went to press. Full details will appear in the next issue in March, 1993:

Mr John B. King, FRCS was elected Chairman of BASM at the Annual General Meeting of BASM at Lilleshall on 27 September 1992.

We regret to learn of the death of our former BASM Honorary Secretary, Mr David P. Chapman. 